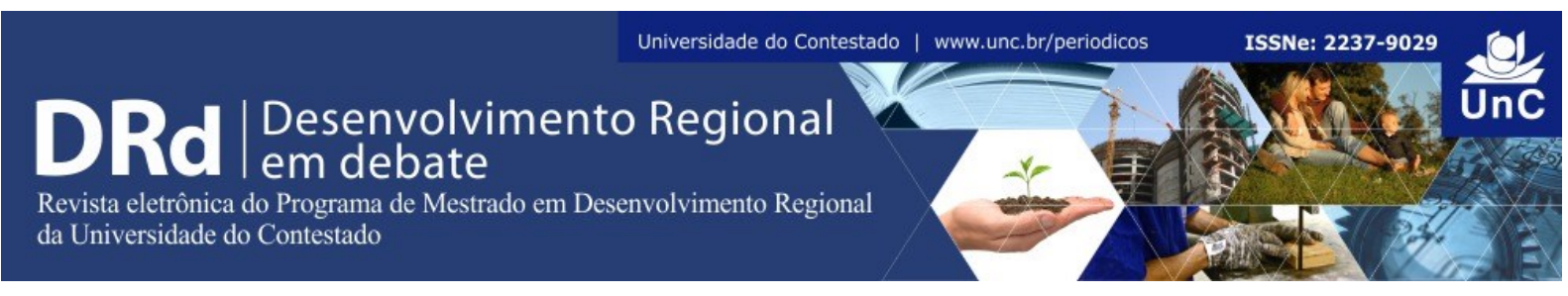

\title{
DOCUMENTO ESTRATÉGICO SOBRE DESENVOLVIMENTO REGIONAL NO TERRITÓRIO DO CONTESTADO
}

\author{
Valdir Roque Dallabrida ${ }^{1}$ \\ Maria Luiza Milani ${ }^{23}$
}

\section{APRESENTAÇÃO}

Inicialmente, é necessário fazer referência ao recorte territorial do Estado de Santa Catarina - SC que denominamos de Território do Contestado. Na figura abaixo, utilizando a referências das Regiões Turísticas do Estado de SC, temos uma aproximação dos municípios que pertencem ao referido território. Considerando características socioeconômicas, ambientais e culturais, outros municípios próximos poderiam ser acrescidos ao recorte territorial em referência.

Figura 1 - Área territorial abrangida pelo Território do Contestado no Estado de Santa Catarina

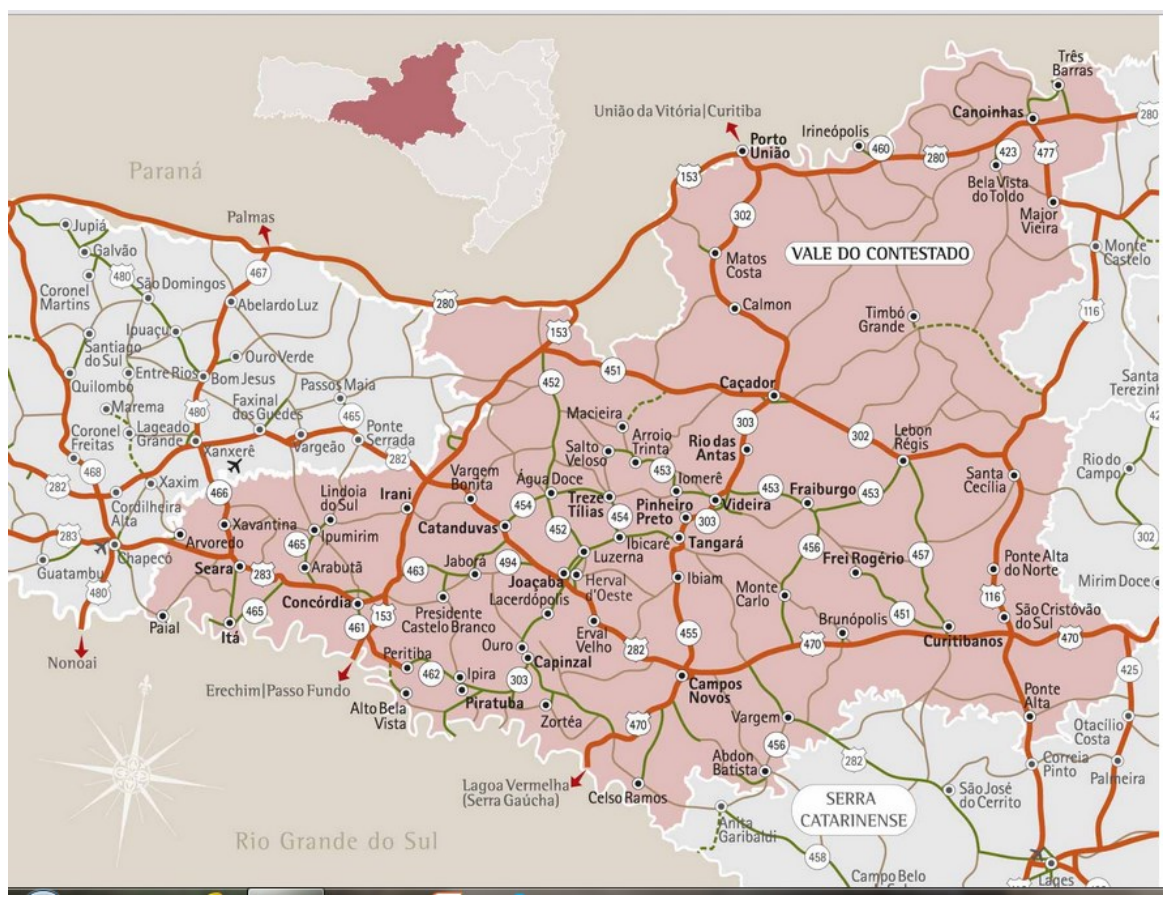

Fonte: Santa Catarina. Região Turística Vale do Contestado (2014)

\footnotetext{
${ }^{1}$ Geógrafo, Doutor em Desenvolvimento Regional, com atuação no Programa de Mestrado em Desenvolvimento Regional da Universidade do Contestado (UnC). Santa Catarina. Brasil. E-mail: valdirroqued897@gmail.com. ${ }^{2}$ Doutora em Serviço Social pela Pontifícia Universidade Católica de São Paulo, com atuação no Programa de Mestrado em Desenvolvimento Regional da Universidade do Contestado (UnC). Santa Catarina. Brasil. E-mail. marialuiza@unc.br

${ }^{3}$ Contribuíram também na elaboração do presente documento os(as) seguintes colegas: Daniela Pedrassani, Jairo Marchesan e Alexandre Assis Tomporoski (UnC), Gilberto Neppel (Epagri), Graciele Viccini Isaka, Magali Regina e Cláudia Kuns Tomazelli (IFSC-Canoinhas).
}

DRd - Desenvolvimento Regional em debate (ISSNe 2237-9029)

v. 6, n. 2, ed. esp., p. 26-33, jul. 2016. 
Durante os dias 20 a 22 de agosto/2014, realizou-se no Hotel Santa Catarina de Canoinhas o III Workshop sobre Desenvolvimento Regional no Território do Contestado e II Seminário Sistemas de Produção Tradicionais e Agroflorestais no Centro-Sul do Paraná e Norte Catarinense. O evento foi promovido pelo Mestrado em Desenvolvimento Regional da Universidade do Contestado (UnC), a Universidad Gastón Dachary de Posadas (Argentina) e a Empresa de Pesquisa Agropecuária e Extensão Rural do Estado de Santa Catarina (EPAGRI), com apoio do Ministério da Agricultura, Pecuária e Abastecimento (MAPA). Como instituições apoiadoras, tivemos ainda a Associação dos Municípios do Planalto Norte Catarinense (AMPLANORTE), o Instituto Federal Santa Catarina (IFSC), o Banco do Brasil e o Sindicato das Indústrias do Mate (SINDIMATE).

O objetivo do evento foi apresentar, debater e difundir experiências internacionais e nacionais inovadoras, na perspectiva de que as mesmas sirvam de referência para se pensar novas alternativas de desenvolvimento territorial para o Estado de Santa Catarina, em especial as regiões estagnadas, como o caso do Território do Contestado. Neste sentido, apresenta-se este documento, o qual contempla sinteticamente as principais contribuições teórico-práticas apresentadas pelas palestras e nas mesas redondas durante o evento. $\mathrm{O}$ presente documento foi disponibilizado às instituições e lideranças regionais, para fundamentar suas reflexões e ações.

\section{SÍNTESE DAS PALESTRAS E MESAS REDONDAS}

Os temas apresentados e debatidos no evento abrangeram um vasto escopo.

Quadro 1 - Síntese Palestras e das Mesas Redondas do III Workshop e II Seminário

\begin{tabular}{|l|l|}
\hline \multicolumn{1}{|c|}{ Tema da Palestra e Palestrante(s) } & \multicolumn{1}{c|}{ Foco da palestra } \\
\hline $\begin{array}{l}\text { Avanços Tecnológicos e Inovações no Setor } \\
\text { da Silvicultura } \\
\text {-Dr. Rafael Alejandro Scherer e Ms. Ana } \\
\text { Alícia Pokolenko (Argentina) }\end{array}$ & $\begin{array}{l}\text { Alternativas ao desenvolvimento regional, apresentando a } \\
\text { experiência argentina na produção agrosilvopastoril e da erva- } \\
\text { mate }\end{array}$ \\
\hline $\begin{array}{l}\text { Usos do Solo e Desenvolvimento Regional } \\
\text {-Dr. Julio Plaza Tabasco (Espanha) }\end{array}$ & $\begin{array}{l}\text { Apresentação da experiência de Castilla-La Mancha na Espanha } \\
\text { e de resultados de investigação realizada no Território do } \\
\text { Contestado, sobre usos do solo }\end{array}$ \\
\hline $\begin{array}{l}\text { O que é um produto certificável como } \\
\text { Indicação Geográfica? } \\
\text {-Dr. Marcelo Champredonde (Argentina) }\end{array}$ & $\begin{array}{l}\text { Abordagem sobre a valorização da tipicidade cultural e } \\
\text { territorial dos produtos, tendo como foco a realidade da } \\
\text { América Latina, em especial da Argentina e do Brasil }\end{array}$ \\
\hline $\begin{array}{l}\text { Estratégias de animação territorial, } \\
\text { empoderamento de atores em áreas rurais com } \\
\text { esvaziamento populacional } \\
\text {-Dra. Hermínia Fernandes Gonçalves } \\
\text { (Portugal) }\end{array}$ & $\begin{array}{l}\text { Experiências de atuação em aldeias rurais do nordeste de } \\
\text { Portugal, aplicável à realidade de territórios rurais no Brasil e } \\
\text { América Latina, com vistas ao desenvolvimento territorial }\end{array}$ \\
\hline $\begin{array}{l}\text { Construção social de um Território Inovador } \\
\text {-Dr. António Covas e Dra. Maria das Mercês } \\
\text { Mendonça Covas }\end{array}$ & $\begin{array}{l}\text { Experiência da região portuguesa do Algarve, destacando a } \\
\text { tendilização de estagiários residentes, egressos da graduação, } \\
\text { contraposição aos "territórios zona", entendendo os primeiros } \\
\text { como âmbitos territoriais em que haja uma articulação } \\
\text { interinstitucional no processo de desenvolvimento e, os } \\
\text { segundos, os recortes territoriais em que predominam ainda as }\end{array}$ \\
\hline
\end{tabular}

DRd - Desenvolvimento Regional em debate (ISSNe 2237-9029) 


\begin{tabular}{|c|c|c|c|}
\hline & & \multicolumn{2}{|c|}{$\begin{array}{l}\text { tradicionais políticas de desenvolvimento regional } \\
\text { setorializadas }\end{array}$} \\
\hline \multicolumn{2}{|c|}{$\begin{array}{l}\text { O papel das Associações de Desenvolvimento } \\
\text { Local e Regional, como estrutura } \\
\text { organizacional e funcional inovadora de } \\
\text { gestão do desenvolvimento territorial } \\
\text {-Dr. Jorge Revez (Portugal) }\end{array}$} & \multicolumn{2}{|c|}{$\begin{array}{l}\text { Experiência de Portugal, a qual serve de referência para rever } \\
\text { práticas de conselhos ou fóruns de desenvolvimento, como os } \\
\text { representados pelas Secretarias de Desenvolvimento Regional } \\
\text { do Estado de Santa Catarina, com destaque para a questão da } \\
\text { representatividade social, institucional e corporativa e a } \\
\text { participação democrática dos cidadãos nas decisões territoriais. }\end{array}$} \\
\hline \multicolumn{4}{|c|}{ MESAS REDONDAS } \\
\hline Tema da Mesa & \multicolumn{2}{|c|}{ Foco da Mesa } & Participantes \\
\hline $\begin{array}{l}\text { Sistemas de Produção } \\
\text { Tradicionais e } \\
\text { Agroflorestais e impactos no } \\
\text { Desenvolvimento Territorial }\end{array}$ & \multicolumn{2}{|c|}{$\begin{array}{l}\text { Apresentação de experiências } \\
\text { inovadoras dos Estados de } \\
\text { Santa Catarina e do Paraná }\end{array}$} & $\begin{array}{l}\text { Representantes da EMBRAPA, IAPAR, } \\
\text { EMATER, ICMBio e EPAGRI }\end{array}$ \\
\hline $\begin{array}{l}\text { A indicação Geográfica } \\
\text { como alternativa de } \\
\text { Desenvolvimento Territorial }\end{array}$ & \multicolumn{2}{|c|}{$\begin{array}{l}\text { Apresentação de experiências } \\
\text { catarinenses, o caso do Vale } \\
\text { da Uva Goethe (Urussanga), } \\
\text { do Queijo Serrano (Serra } \\
\text { Catarinense e Rio-grandense) } \\
\text { e da Erva-mate (Planalto } \\
\text { Norte Catarinense e Centro- } \\
\text { Sul do Paraná }\end{array}$} & $\begin{array}{l}\text { Representantes da EPAGRI e UnC, mais o Dr. } \\
\text { Paulo Niederle (UFRGS), Dr. Flávio Sacco dos } \\
\text { Anjos (UFPEL) e Dra. Helena Schiavone } \\
\text { (Argentina) }\end{array}$ \\
\hline $\begin{array}{l}\text { Experiências internacionais } \\
\text { de desenvolvimento local e } \\
\text { regional e sua aplicabilidade } \\
\text { no Território do Contestado }\end{array}$ & \multicolumn{2}{|c|}{$\begin{array}{l}\text { Mesa Redonda que finalizou o } \\
\text { evento, apresentando os } \\
\text { destaques das contribuições do } \\
\text { evento, desde o ponto de vista } \\
\text { de representantes das } \\
\text { instituições que } \\
\text { acompanharam o evento }\end{array}$} & $\begin{array}{l}\text { Representantes da EMBRAPA, IAPAR, } \\
\text { EMATER, ICMBio, EPAGRI e do Mestrado da } \\
\text { UnC }\end{array}$ \\
\hline
\end{tabular}

Fonte: Dallabrida e Milani (2014)

Figura 2 - Registro da presença de autoridades e participantes do III Workshop e II Seminário
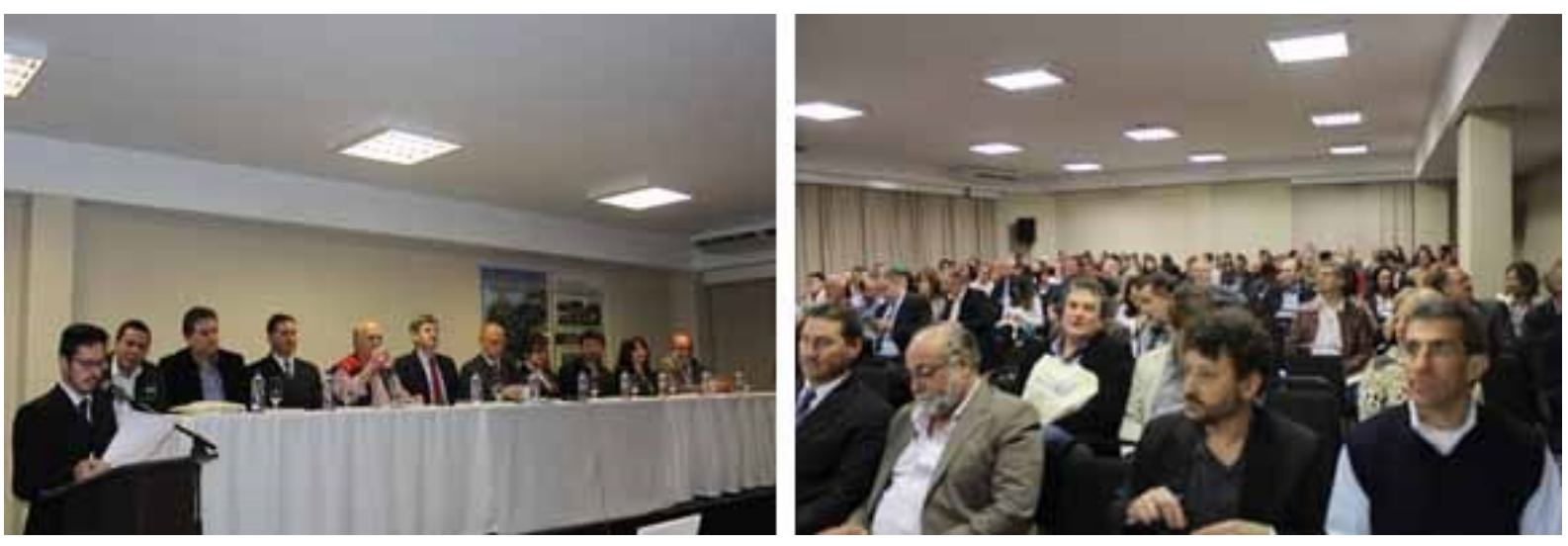

Fonte: Acervo Organizadores do evento (2014)

DRd - Desenvolvimento Regional em debate (ISSNe 2237-9029) 
$\mathrm{Na}$ Figura 2, à esquerda foto da abertura do evento, com as autoridades presentes e instituições promotoras. À direita, parte do público que participou do evento nas dependências do Hotel Santa Catarina de Canoinhas.

\section{PRINCIPAIS APORTES TEÓRICO-PRÁTICOS OPORTUNIZADOS PELO EVENTO}

No contexto das abordagens teóricas e das experiências, tanto nacionais como internacionais, as questões relatadas evidenciaram desafios para o desenvolvimento no Território do Contestado, focados na produção agropecuária e agrosilvopastoril, na geração de trabalho e renda, no bem estar humano e social, no pertencimento territorial em relação às diversidades culturais, nos desafios relacionados ao capital humano e social.

Neste sentido, podem ser destacadas as ideias-força:

3.1 Necessidade de interação entre identidade territorial e diversidade cultural, nos territórios e nas redes que se formam nos mesmos.

3.2 A importância de que os Sistemas Agroflorestais Tradicionais sejam manejados respeitando a identidade sociocultural e ambiental, destacando os recursos e ativos com especificidade territorial.

3.3 A necessidade de mudanças nas formas de utilização do solo, tendo em vista o desenvolvimento sustentável e como instrumento de superação dos desafios.

3.4 O desenvolvimento regional precisa estar referenciado no envolvimento social, quando se faz necessário fazer com os atores territoriais e não para eles, tendo como referência a política, ou seja, ações dos homens promovendo o bem comum.

3.5 A parceria público-privada deve ser concebida como uma ferramenta de desenvolvimento territorial, pois o Estado não resolve tudo, necessitando envolvimento social e institucional articulado.

3.6 É necessário enfrentar adequadamente os paradoxos existentes na produção agropecuária, na relação entre desenvolvimento tecnológico, na manutenção dos sistemas tradicionais de produção artesanal, pois a inovação territorial, não necessariamente implica em substituir formas tradicionais de produzir por tecnificação.

3.7 Nos sistemas de produção regionais é necessário assumir a dimensão da multifuncionalidade, ou seja, repensar a organização das propriedades rurais para criar diversificação e densidade econômica, integrando atividades, tais como entre agricultura, pecuária, áreas de preservação ambiental, agrossilvicultura e turismo rural.

3.8 Necessidade de estabelecer relações de equilíbrio entre a pressão da sociedade e das leis para a preservação dos recursos naturais, a conservação das matas 
remanescentes, a preservação de culturas agrícolas tradicionais e a manutenção de áreas de reserva, com o apoio a formatação regional de sistemas de manejo agroflorestal sustentáveis, social e economicamente.

3.9 Em relação a erva-mate são necessários mais estudos e divulgação dos avanços tecnológicos nacionais e internacionais em relação aos sistemas de produção tradicionais e agroecológicos, com especial atenção à produção familiar.

3.10 Há necessidade de reforço às lógicas de participação comunitária e de cooperação interterritorial, priorizando abordagens participativas de reflexão-ação nas ações voltadas ao desenvolvimento territorial.

3.11 As instituições têm o papel de liderar, articuladamente, processos de ativação dos recursos e ativos territoriais, valorizando os fatores humano, social, cultural, econômico e ambiental.

3.12 A Indicação Geográfica pode ser vista como ferramenta de desenvolvimento territorial, não como fator único, oportunizando a participação dos diferentes elos da cadeia produtiva no processo de estruturação e reconhecimento da mesma.

3.13 Um dos argumentos proferidos numa das palestras, aqual pode servir como referencial na nossa reflexão sobre desenvolvimento, é que o modo de olharmos o problema, já é parte do problema, podendo resultar em ações mais ou menos efetivas, além do fato de que não há problema que se resolva somente no plano local ou territorial, o que pode demandar visões e ações multiterritoriais.

3.14 Nossos recortes territoriais, para os quais se dirigem as ações de desenvolvimento, precisam se transformar em territórios-rede, utilizando-se como referência, ações integradas e articuladas pelos atores e instituições, superando ações setorializadas, próprias dos ultrapassados territórios-zona.

3.15 É necessário que nos desafiemos a fazer o impossível, ou seja, superar os desafios impostos pela burocracia, sermos inovadores, fazendo o diferente e tendo a coragem de tentar fazer o novo, mesmo que não tenhamos certeza do sucesso.

3.16 Os conflitos existem em todo o lugar e tempo, não podemos fugir deles; precisamos administrá-los, com consciência de que nem todos têm a solução rápida, nem mesmo necessariamente deixarão de existir.

3.17 As experiências internacionais de desenvolvimento territorial não são necessariamente replicáveis, no entanto, o modo de fazer pode inspirar-nos a fazer melhor e superar os desafios regionais.

3.18 Independentemente do padrão tecnológico que se utilize na produção industrial, agropecuária ou silvopastoril, é indispensável o foco central na agregação de valor aos produtos que comercializamos com outras regiões ou que exportamos, a fim de superar a tradição extrativista e exportadora de commodities de baixo valor agregado, historicamente presente no Território do Contestado. 


\section{INDICATIVOS DE DESENVOLVIMENTO NO TERRITÓRIO DO CONTESTADO, REFERENCIADOS NAS EXPERIÊNCIAS E REFLEXÕES OPORTUNIZADAS NO EVENTO}

No processo de desenvolvimento no Território do Contestado há paradoxos, potencialidades e distanciamentos, pois os ambientes apresentam situações diversificadas, complexas, complementares e cooperativas. Historicamente, a região esteve fortemente voltada ao extrativismo e à produção agropecuária tradicional. Nas últimas décadas ocorreu a substituição de culturas nativas, tais como, a araucária e a erva-mate, por monoculturas silvícolas (pinus e eucalipto) e fumo. Com essas substituições ocorreu o reordenamento industrial, com destaque para o processamento do pinus em maior escala, e da erva-mate e fumo em plano secundário, projetando novos desafios ao desenvolvimento.

Paralelamente, no Território do Contestado, em especial no meio rural, duas novas realidades se sobressaem: o empobrecimento dos produtores rurais pela sua descapitalização e a masculinização e envelhecimento da população do meio rural, evidenciando um viés de gênero e sucessão, importantes no planejamento e intervenções com vistas ao desenvolvimento territorial. Além disso, novas configurações sociais se constituem, aumentando os assentamentos urbanos precários.

Outro desafio no Território do Contestado é sua escassa articulação intrarregional e com outros centros dinâmicos socioeconomicamente, resultado, em parte, do fato de ficar fora das grandes rotas de ligação de transporte e circulação.

Parte dos desafios, também, recai sobre os baixos níveis de capital social, somado à cultura imediatista, o que esbarra nas fragilidades do capital humano, resultando em níveis insuficientes de democracia participativa nos processos de desenvolvimento dos territórios.

Portanto, urge constituir processos de melhora da autoestima local-regional e territorial, ampliando a capacidade de identificar as questões que não contribuem para os avanços necessários em termos de desenvolvimento, evidenciando e valorizando o potencial produtivo, não apenas de matérias-primas e produtos semi-industrializados, mas reconhecendo e estimulando a capacidade de produzir outros produtos com maior valor agregado. Neste sentido, o fio condutor para o desenvolvimento precisa voltar-se à lógica da cultura da paciência histórica, valorizando as distintas vozes, aprendendo, ouvindo, conhecendo e dialogando com os atores e instituições, a fim de interferir positivamente sobre o meio urbano e rural.

Neste sentido, sustentado em experiências apresentadas e nos debates oportunizados no evento em referência, apontamos alguns indicativos:

1. Em relação a um dos nossos produtos tradicionais, estudos já evidenciaram que a erva-mate nativa, ou sombreada, perfaz mais de $80 \%$ da área ocupada no Planalto Norte Catarinense e Centro-Sul do Paraná, o que se apresenta como o principal diferencial, comparado a outras regiões produtoras do Brasil e América Latina. Outro diferencial é que em torno de $90 \%$ destas áreas tratam-se de ervais agroecológicos, que não utilizam agroquímicos no seu cultivo, além do fato de que predomina a genética de plantas originais da região. Estes diferenciais devem ser considerados na definição dos parâmetros para a constituição da Indicação Geográfica que se pretende. Assim, teremos um produto diferenciado, com mais 
notoriedade, logo, mais valorizado pelo mercado consumidor. Ou seja, quanto mais se ajusta os critérios para a definição da Indicação Geográfica à tipicidade territorial, maior a valorização do produto erva-mate e maior será a geração de emprego e renda, contribuindo para o desenvolvimento territorial, com preservação ambiental. Certamente, serão necessários estudos, investigações em melhoramentos genéticos, sobre geração de novos produtos, além de outros, no que se espera a contribuição das instituições de pesquisa acadêmica e extensão rural. Considerando que a paisagem florestal da erva-mate se estende, com mais intensidade, do Planalto Norte Catarinense ao Centro-Sul do Paraná, são necessárias ações integradas interestadualmente.

2. As áreas predominantemente agrícolas do Território do Contestado, precisam: (i) tornarem-se atividades produtivas de maior valor agregado; (ii) atribuir a elas outras funcionalidades além de produzir alimentos, gerando novas alternativas de renda para os agricultores, tais como a compensação pela preservação ambiental, o incentivo ao turismo rural apoiado na culinária caracteristicamente regional.

3. O desenvolvimento resulta de ações e estudos transdisciplinares, exigindo o envolvimento de todos os setores, das instituições de ensino, de pesquisa e de extensão, assumindo o compromisso de aprender, ouvir, refletir, interagir e trabalhar coletivamente com as comunidades. Assim, deve haver uma definição da visão de futuro: o que queremos para as gerações futuras no Território do Contestado? É possível conjecturar que o desenvolvimento territorial com geração de renda de forma sustentável, social, econômica, cultural e ambientalmente, seria o indicado.

4. Um dos aspectos fundamentais é pensarmos as ações de desenvolvimento territorial na perspectiva da pluriatividade, com competitividade, equilíbrio e conservação socioambiental. Assim, a reestruturação produtiva regional passa pela necessidade urgente de qualificação técnica e cultural do pessoal envolvido, com remuneração adequada, intensificando a educação formal e ampliando estratégias de educação informal que levem à compreensão da realidade e de seus problemas e que respalde a busca por soluções. Deve-se construir e estabelecer relações de democracia e participação das comunidades rurais, promovendo a governança territorial colaborativa. Na esfera pública, a articulação deve estar voltada para o estabelecimento de uma postura inovadora e ousada.

5. No processo de busca do desenvolvimento no Território do Contestado é imperativo fortalecer o trabalho em parceria, com a sensibilização dos atores envolvidos para que estes se sintam parte do processo e colaborem com a construção de propostas nas quais os atores possam se identificar, participar no ato de planejar, visando soluções para os problemas locais, regionais ou territoriais.

6. Na concepção dos projetos e/ou programas de desenvolvimento territorial deve ficar visível aos atores, que o objetivo maior é a melhoria da qualidade de vida das pessoas, da comunidade e da sociedade como um todo. $\mathrm{Na}$ construção de alternativas para enfrentar os desafios relacionados ao desenvolvimento do Território do Contestado, estrategicamente, os atores envolvidos devem ouvir e refletir com as comunidades suas apreensões. A partir dessas, estabelecer objetivos 
precisos, de fácil aplicação e com resultados no curto prazo, para se obter a confiança no processo. É indispensável que os atores se sintam desafiados para intervenções ousadas e inovadoras.

7. Da mesma forma que ações do passado voltadas ao desenvolvimento regional, caracterizadas pela invisibilidade dos povos tradicionais (os chamados caboclos), hoje é necessário no Território do Contestado evitar formas de exclusão de setores fragilizados, ou seja, ao invés da invisibilidade, é necessário o empoderamento social, tornando-os sujeitos e protagonistas dos processos.

8. Por fim, são necessárias mais ações com vistas à recuperação e rememorização da História do Contestado, para que os bons valores evidenciados na História possam servir de referencial nas nossas ações territoriais contemporâneas.

9. Por fim, as instituições promotoras do III Workshop sobre Desenvolvimento Regional no Território do Contestado e II Seminário Sistemas de Produção Tradicionais e Agroflorestais no Centro-Sul do Paraná e Norte Catarinense, se comprometem a serem parceiras na consecução dos indicativos aqui evidenciados, além de divulgar junto às demais instituições públicas e privadas tais reflexões e proposições.

Canoinhas-SC, 22 de agosto de 2014.

Entidades Signatárias: UnC, EPAGRI Regional de Canoinhas, MAPA-Superintendência do Estado de Santa Catarina, EMBRAPA Florestas, EMATER Paraná, IFSC e AMPLANORTE. 